\title{
Strengthening and redesigning flood risk governance in Europe: an overview of seven key issues and how they are being dealt with in six European countries
}

\author{
Dries Hegger ${ }^{1 a}$, Peter Driessen ${ }^{1}$, Marloes Bakker ${ }^{1}$ and Carel Dieperink ${ }^{1}$ \\ ${ }^{1}$ Environmental Governance, Copernicus Institute of Sustainable Development, Utrecht University
}

\begin{abstract}
European countries, especially urban areas, face increasing flood risks due to urbanization, increase of exposure and damage potential, and the effects of climate change. In literature and in practice, it is argued that a diversification of Flood Risk Management Strategies (FRMSs) makes countries more flood resilient. The latter requires innovations in existing Flood Risk Governance Arrangements, development of new arrangements and the coordination of these arrangements, but it also requires these arrangements to be tailored to their physical and institutional context. Within the EU FP7 project STAR-FLOOD (2012-2016), a comparative analysis and evaluation of flood risk governance in Belgium, England, France, The Netherlands, Poland and Sweden has been conducted. The project identified at least seven key issues that are relevant for all researched countries (and probably also beyond). These key issues deal with the topics of (i) diversifying Flood Risk Management Strategies (ii) establishing connectivity between actors, levels and sectors through what we coin "bridging mechanisms"; (iii) achieving coproduction between public and private actors; (iv) improving fragmented and often non-enforceable rule systems; (v) optimising available resources for FRM; (vi) operationalising the notion of "diversification of FRM strategies" in a country-specific way; (vii) follow general design principles for improving FRM that are sufficiently tailored to local circumstances. Drawing on all project deliverables, this paper will briefly review each key issue, discuss salient similarities and differences between the countries and point at ways forward.
\end{abstract}

\section{Introduction}

This report discusses the key conclusions of the EU FP7 project STAR-FLOOD. This project focused on analysing, explaining, evaluating and designing flood risk governance in six European countries: Belgium, England, France, The Netherlands, Poland and Sweden $[1,2]$. The key conclusions are intended to help develop policy design principles for flood risk governance arrangements and to derive implications for policies and law at the level of the EU, its member states, regional authorities, and public-private partnerships. In so doing, the report reflects on two starting assumptions of the project (see box 1) [1]:

\section{Box 1: STAR-FLOOD's starting assumptions [1]}

Assumption 1: Societal resilience to floods is enhanced if multiple Flood Risk Management Strategies are implemented simultaneously and are aligned.

Assumption 2: A successful implementation of a diverse, resilient, set of FRSs - requiring a combination of old and new strategies and coordination of different strategies - in a certain area is only possible if these strategies and their coordination are appropriate. They should enhance make efficient use of re-sources and should be considered legitimate by actors involved, thus ensuring proper institutional embedding given the opportunities and constraints of their physical and social context.

Both starting assumptions have been derived from current debates in literature, policies (including the EU Floods Directive, Directive 2007/60/EC) and practice on flood

\footnotetext{
${ }^{a}$ Corresponding author: d.l.t.hegger@uu.nl
}

risk governance in times of increasing flood risks due to urbanisation and the effects of climate change. Riskbased approaches to flood risk management are emerging that address exposure, likelihood and magnitude of flood hazards as well as the consequences should floods occur [2-6]. While flood defence focuses on reducing the likelihood of floods, additional strategies help to take into account the other aspects of flood risk. Flood prevention helps to reduce exposure; flood mitigation focuses on the magnitude of the flood hazard; while flood preparation and recovery both deal with the potential consequences of floods [2]. Strategies should, however, be implemented in such a way that they fit in their physical and institutional contexts. Our key findings, which have been listed below, provide the building blocks for scrutinising and elaborating the two starting assumptions. To each key finding, a separate section has been devoted, providing an explanation of each key finding and referring to those STAR-FLOOD products that provide the main evidence for this finding.

\section{Necessity and importance of a diversification of Flood Risk Management Strategies}

The research conducted within STAR-FLOOD has shown that Diversification of Flood Risk Management Strategies is indeed necessary and important [7-13]. Not all floods can be prevented and flood risks are increasing tremendously in all STAR-FLOOD consortium countries. In order to be resilient, a country should have the capacity to resist, absorb and recover and to adapt $[7,14$, 15]. In practice this means that the country cannot rely on only one strategy. But it also means that sufficient 
investment in each chosen strategy needs to be provided. Diversification should not lead to a spreading of resources which results in an underinvestment in all strategies [16]. However, the precise meaning of the term "diversification" differs per country. In England and Sweden, diversification is the key strategy in that the aim is to have a balanced portfolio consisting of all strategies in place. In the other four researched countries, diversification means that a dominant strategy (often defence) is complemented with other strategies [7-13]. In most cases, the practical on the ground implementation of these "back-up strategies" is lagging behind discursive shifts observed in policy documents [7-13].

\section{Establishing connectivity between actors, levels and sectors through bridging mechanisms}

Diversification of FRM strategies may lead to fragmentation between actors, levels and sectors. Such fragmentation could lead to inefficiencies and even ineffectiveness, which in turn could undermine societal resilience [7-13, 16, 17]. To counteract this fragmentation, bridging processes and mechanisms are needed. These bridging processes and mechanisms include coordinating actors; procedural duties and instruments; formal rules and regulations; financial and knowledge resources and bridging concepts, amongst others [17]. Fragmentation as currently found may be seen as a transitional stage in the sense that diversification has entered policy agendas relatively recently. Actors in several countries and regions now seem on a steep learning curve. We expect that fragmentation may be overcome, provided that further learning, cooperation and exchange between countries take place [16]. To bridge different levels of government, subsidiarity in flood risk governance needs to be enhanced. The shifting of financial and executive tasks from higher to lower levels of governments as found in several countries needs to be accompanied with a shifting of formal powers [16]. This notwithstanding, a good combination of top-down and bottom-up working is needed whereby strategic discussions and the maintaining of a strategic overview at the catchment level is in the hands of higher levels of governments, but bottom-up work is done by local stakeholders $[16,17]$.

\section{Involvement of business, NGOs and citizens in FRM}

The issue of broader actor involvement in FRM, whereby private actors, including business, NGOs and citizens are becoming involved next to governmental actors, is now high on political agendas, including those of the European Commission. This is partly related to more general societal developments, amongst other factors to broader shifts in discourses about governance. Besides that, diversification of FRM strategies in many cases requires the involvement of these other actors. Their involvement is often necessary for substantive reasons (e.g. because governments do not have a formal competence to act; and because some measures, e.g. on private properties, can only be implemented by private parties) [18]. Also, investments by private parties are often needed due to cuts in government spending. These issues link to broader debates on the extent to which flood risk management is to be seen as an individual versus a collective responsibility. Another issue is that, in Europe participation in decision making is considered important (Aarhus convention on Access to Information, Public Participation in Decision-Making and Access to Justice in Environmental Matters). [19] For that reason, to achieve legitimate flood risk governance, governments cannot steer exclusively in a top-down fashion but need to involve other actors in decision-making [16, 18]. Based on our research, we suggest interpreting publicprivate cooperation as 'multi-actor coproduction'. This interpretation seems more productive than the, much more narrow, interpretation of 'letting market parties/companies do more in flood risk governance' [16, 18]. We also noticed a broader trend of shifting responsibilities between governments and citizens. Since we notice that this trend is often latent, we recommend having on open, broad (political and societal) debate about these shifting responsibilities. The outcome of the debate should lead to more clearly defined roles for governments/citizens, ideally to be laid down in either law or policy documents [16].

\section{Diversification in rules and regulations related to FRM}

Diversification of Flood Risk Management Strategies is accompanied with a diversification in rules and regulations. Some rules may serve as bridging mechanisms but on the other hand new rules have also been found to increase complexity [16]. In addition, in some cases a lack of rules can be witnessed, especially in cases in which certain strategies have not yet been implemented to a significant extent [16]. The Floods Directive (Directive 2007/60/EC) [20] has facilitated the implementation of FRM strategies in all STAR-FLOOD countries, but especially in those countries where FRM is not yet mature (including Sweden and Poland) [8-13, 16, $20,21]$. The findings from the STAR-FLOOD project suggest that the current scope of the Floods Directive, which poses non-substantive requirements to EU Member States, is in general appropriate. In most cases Flood Risk Management Strategies need to be tailored to specific local circumstances and hence the substantive content of national and regional FRM approaches cannot be prescribed at the European level. In contrast, with respect to the requirements related to cooperation in International River Basin Districts, the Floods Directive could go further in terms of substantive requirements. In shared river basins, the fully fledged procedural approach whereby Member States have full discretionary powers and no substantive cooperation requirements to implement FRM strategies and measures would not be justified, since measures promulgated in one country could have visible effects in other countries in the same 
river basin [16, 21]. Another possibility for strengthening the Floods Directive would be to consider some safeguard mechanisms with regard to access to justice $[16,21]$.

The subsidiarity principle states that decisions should be taken as closely as possible to the citizen. On paper, this principle is widely endorsed, not only at the level of the EU but also at the national level in many European countries. In reality, however, flood risk management within several European countries (e.g. England, France) still holds to a strong top-down approach. Instead, national governments or the EU could act more as a supportive actor by supporting (funding and expertise) and approving flood risk policy planning at local level (preferably within hydrological boundaries). Our recommendation is to pursue the principle of subsidiarity more ambitiously, given the finding that local, tailormade solutions are often the best way of detangling multi-actor, multi-sector and multi-level governance problems in flood risk governance [16].

\section{Availability of different types of resources}

The availability of different types of resources, amongst other things in terms of finance, knowledge, skills and ICT tools, but also in terms of political legitimacy, is an important determinant of the extent to which FRM strategies are being developed, implemented and linked to other strategies since they affect the power basis of actors [2]. Available resources should be mobilised efficiently and their availability should be increased, if possible [16]. The availability of financial resources differs significantly between the STAR-FLOOD countries. Some countries have well-established systems for funding specific FRM strategies (e.g. France, England, The Netherlands), whereas other countries (e.g. Poland) are highly dependent on European funds like the Solidarity Fund and the EU cohesion fund [8-13, 16]. Knowledge is another crucial resource. In terms of this resource, The Netherlands can be said to have an optimally developed knowledge infrastructure while in the other countries there is still significant room for improvement [8-13, 16]. An important policy issue for the coming years will be to have political debate and make political choices in order to combine the (perceived and sometimes already legally settled) 'right to be protected' of citizens versus the increasing financial scarcity and the pressure to focus on priorities [16]. Resources might also play a key role in bridging, for instance by ensuring that actors involved have the necessary skills, that that private actors receive sufficient payment to increase their willingness to let their land function as flood storage [17].

\section{The link between diversification of FRM strategies and resilience}

In terms of STAR-FLOOD's first starting assumption, we found that diversification of strategies can be seen as a necessary precondition for enhancing societal resilience to floods. However, while diversification contributes to resilience, it does not automatically lead to it. We stress that resilience comes with three capacities: capacity to resist, capacity to absorb/recover and capacity to adapt [7, $14,15]$. These are to be seen as different rationales and normative starting points for flood risk governance and, moreover, our empirical data suggest that these are to some extent mutually exclusive. We cannot point at country that score high or low on all three capacities, hence it would not be legitimate to make statements in terms of "country A is more resilient than country B" [7, 8-13]. Second, to evaluate flood resilience, besides the mere presence of FRM strategies, issues of dominance of strategies; their feasibility in specific physical circumstances and their fit in existing institutional contexts (appropriateness) should be considered [2]. Related to this, we have found that to some extent a high score on one capacity (to resist) may even undermine that of other capacities (e.g. absorb and recover) [7, 8-13]. Finally, the presence (or the absence) of links between strategies has turned out to be a crucial factor explaining countries' achievements on all three capacities [17]. Obviously, enhancing societal resilience through diversification requires sufficient investment in each of these strategies and alertness for the risk of underinvestment of all of them [16].

\section{Design principles for improving FRM strategies}

Several design principles for improving FRM strategies on the local, regional, national and European level have been identified. These should ensure that FRM is resilient, efficient and legitimate [22]. To improve resilience, there is: i) a need to establish adaptive management to aid the implementation of defence and mitigation measures that are tailored to local circumstances; ii) a need to design spatial planning in such a way that consequences are prevented and minimised if floods occur; iii) a need for further improving systems for forecasting, warning and emergency responses that are proactive, risk-based and use collaborative approaches, for instance by optimising the use of ICT (apps); iv) a need for having strategies to recover from flood events available for all citizens while at the same time ensuring that these provide sufficient incentives for citizens in order not to dis-incentivise prevention and mitigation measures; v) a need for institutional systems that foster learning and innovation. Resource efficiency requires that the level of flood risk management is secured that is found acceptable by societal actors at the lowest possible societal costs and against the highest possible societal benefits, looking for synergies, e.g. though multi-use flood alleviation schemes. Legitimacy requires that the decision making 
process is characterised by a high degree of public participation, fairness and accessibility. The approach should be generally accepted by the public, open and transparent, access to risk information should be ensured, and there should be mechanisms in place to ensure social equity. A potential action perspective is to approach citizens as equal partners that co-produce FRM measures together with governmental actors and (other) private parties [22].

\section{Concluding remarks}

Social scientific and legal research, especially governance research, on FRM had received limited attention vis-à-vis natural science research. Adopting a governance perspective has shown to provide important complementary insights that may help to improve FRM approaches in different countries. STAR-FLOOD shed some light on, and helped address the following issues in particular [16]:

-No one size fits all solutions. Not all FRM strategies are feasible and desirable anywhere. Besides physical/geographical factors, also historical pathways in dealing with flood risks, normative viewpoints on acceptable levels of risk, administrative and legal frameworks and cultures are important factors that influence the directions FRM approaches in countries and regions can take. These also have implications for how policies and legal frameworks should be shaped and, as chapters 6 and 7 have shown, the desirable scope of European policies and funding schemes.

-The need to develop connectivity. The issue of diversification of FRM strategies in the face of urbanisation and climate change inevitably involves multi-level, multi-actor and multisector governance challenges. Issues that turned out to be especially crucial are: the link between actors levels and sectors, including involvement of private parties / citizens in FRM, holistic spatial planning that takes flood risks into account, multi-level governance systems that balance the need for local flexibility and coordination. All these issues point at the need to establish connectivity between actors, levels and sectors.

-The need to consider the "social" in "socialecological resilience". The STAR-FLOOD findings have reconfirmed that resilience is a multi-faceted concept that is closely connected to normative views held in societies on what forms of resilience are seen as desirable, what levels of risk are deemed acceptable and who is responsible for carrying these risks (e.g. the individual, or society as a whole).

\section{References}

1. Hegger, D. L. T., Green, C., Driessen, P. P. J., Bakker, M. H. N., Dieperink, C., Crabbé, A., Deketelaere, K., Delvaux, B., Suykens, C., Beyers, J. C., Fournier, M., Larrue, C., Manson, C., Van Doorn-Hoekveld, W., Van Rijswick, H. F. M. W., Kundzewicz, Z.W. and Goytia-Casermeiro, S., (2013). Flood Risk Management in Europe: Similarities and Differences between the STARFLOOD consortium countries. STAR-FLOOD Consortium, Utrecht, The Netherlands.

2. Hegger, D. L. T., Driessen, P. P. J., Dieperink, C., Wiering, M., Raadgever, G. T. and Van Rijswick, H. F. M. W. (2014). Assessing stability and dynamics in flood risk governance: an empirically illustrated research approach. Water Resources Management Vol. 28, pp. 4127-4142. http://dx.doi.org/10.1007/s11269-014-0732-x.

3. Aerts, J. C. J. H., Botzen, W., Van Der Veen, A., Krykow, J. and Werners, S. (2008). Dealing with uncertainty in flood management through diversification. Ecology and Society Vol. 13, no. 1, pp. 41.

4. Innocenti, D. and Albrito, P. (2011). Reducing the risks posed by natural hazards and climate change: the need for a participatory dialogue between the scientific community and policy makers. Environmental Science \& Policy Vol. 14, pp. 730733. doi:10.1016/j.envsci.2010.12.010.

5. Wardekker, J. A., De Jong, A., Knoop, J. M. and Van der Sluijs, J. P. (2010). Operationalising a resilience approach to adapting an urban delta to uncertain climate changes. Technological Forecasting and Social Change Vol. 77, pp. 987998.

http://dx.doi.org/10.1016/j.techfore.2009.11.005.

6. Van Den Brink, M., Termeer, C. A. J. M. and Meijerink, S. (2011). Are Dutch water safety institutions pre-pared for climate change? Journal of Water and Climate Change Vol. 2, pp. 272-287.

7. Hegger, D. L. T., Driessen, P. P. J., Wiering, M., Van Rijswick, H. F. M. W., Kundzewicz, Z. W., Matczak, P., Crabbé, A., Raadgever, G.T., Bakker, M. H. N., Priest, S. J., Larrue, C. and Ek, K. (submitted). Toward more flood resilience: is a diversification of FRM strategies the way forward? Ecology and Society.

8. Mees, H., Suykens, C., Beyers, J. C., Crabbé, A., Delvaux, B., and Deketelaere, K. (2015). Analysing and evaluating flood risk governance in Belgium. Dealing with flood risks in an urbanised and institutionally complex country. University Antwerp, KU Leuven, Belgium, available online via www.starflood.eu.

9. Alexander, M., Priest, S., Micou, A. P., Tapsell, S., Green, C., Parker, D. and Homewood, S. (2015). Analysing and evaluating flood risk governance in England - Enhancing societal resilience through comprehensive and aligned flood risk governance. STAR-FLOOD Consortium. Flood Hazard Research 
Centre, Middlesex University, available online via www.starflood.eu.

10. Larrue, C., Bruzzone, S., Lévy, L., Gralepois, M., Schellenberger, T., Trémorin, J. B., Fournier, M., Manson, C. and Thuillier, T. (2015). Analysing and evaluating Flood Risk Governance in France: from State Policy to Local Strategies, Tours, France, available online via www.starflood.eu.

11. Kaufmann, M., Van Doorn-Hoekveld, W. J., Gilissen, H. K. and Van Rijswick, H. F. M. W. (2015). Drowning in safety. Analysing and evaluating flood risk governance in the Netherlands. STAR-FLOOD Consortium, Utrecht, The Netherlands, available online via www.starflood.eu.

12. Matczak, P., Lewandowski, J., Choryński, A., Szwed, M. and Kundzewicz, Z. W. (2015). Flood risk governance in Poland: Looking for strategic planning in a country in transition. STAR-FLOOD Consortium, Utrecht, The Netherlands, available online via www.starflood.eu.

13. Ek, K., Goytia, S., Pettersson, M., and Spegel, E. (2015). Analysing and evaluating flood risk governance in Sweden - Adaptation to Climate Change?, STAR-FLOOD Consortium, Utrecht, The Netherlands, available online via www.starflood.eu.

14. Larrue, C., Hegger, D.L.T, Trémorin, J.B (2013), Researching Flood Risk Policies in Europe: a framework and methodology for assessing Flood Risk Governance (report no D2.2.1), STAR-FLOOD Consortium, Utrecht, The Netherlands.

15. Alexander, M., Priest, S. and Mees, H. (2015) Practical guidelines for evaluating flood risk governance. STAR-FLOOD Consortium, Utrecht, The Netherlands.

16. Hegger, D. L. T., Driessen, P. P. J., Bakker, M. H. N. (Eds.). FINAL REPORT: Key conclusions on improving flood risk governance in Europe. STARFLOOD consortium, Utrecht, The Netherlands. (forthcoming).

17. Gilissen, H. K., Alexander, M., Beyers, J. C., Chmielewski, P., Matczak, P., Pettersson, M., Schellenberger, T., Suykens, C. (in preparation). Bridges over Troubled Waters - An Interdisciplinary Framework for Evaluating the Interconnectedness within Fragmented Flood Risk Management Systems.

18. Mees, H., Crabbé, A., Alexander, M., Kaufmann, M., Bruzzone, S., Lévy, L. and Lewandowski, J. (submitted). Co-producing flood risk management through citizen involvement - insights from crosscountry comparison in Europe.

19. Aarhus convention on Access to Information, Public Participation in Decision-Making and Access to Justice in Environmental Matters.

20. Floods Directive (Directive 2007/60/EC).

21. Priest, S., Suykens, C., Rijswick, H. F. M. W., Schellenberger, T., Goytia, S., Kundzewicz, Z. W., Van Doorn-Hoekveld, W., Beyers, J. C., Homewood, S. (submitted). The European Union approach to flood risk management and improving societal resilience: Lessons from the implementation of the Floods Directive in six European countries.
22. Pettersson, M., Ek, K., Suykens, C., Priest, S., Alexander, M. and Pardoe, J. (in preparation). Best practices and design principles for resilient, efficient and legitimate flood risk governance - Lessons from cross-country comparisons. STAR-FLOOD consortium, Utrecht, The Netherlands. 